\title{
ANALISIS DAN PENGUKURAN KESIAPAN SEKOLAH ANAK TAMAN KANAK KANAK
}

\author{
Latifah Nur Ahyani, Rr. Dwi Astuti, Ridwan Budi Pramono \\ Fakultas Psikologi Universitas Muria Kudus \\ latifah.nur@umk.ac.id, dwi.astuti@umk.ac.id, ridwan.budi@umk.ac.id
}

\begin{abstract}
Abstrak
Penelitian ini dilakukan untuk mengetahui seberapa besar tingkat kesiapan sekolah anak. Analisa dilakukan untuk mengetahui kebutuhan yang paling diperlukan untuk meningkatkan kualitas pendidikan prasekolah di kabupaten Kudus. Penelitian ini menggunakan metode pengambilan data kuantitatif dan kualitatif. Data kuantitatif diambil dengan menggunakan alat tes psikologi Denver II, Bender-Gestalt II, Child Development Inventory (CDI), sedangkan data kualitatif menggunakan teknik observasi dan wawancara. Subjek penelitian adalah 40 anak Taman Kanak-Kanak (TK) dengan rincian 20 anak TK A dan 20 anak TK B yang terdiri dari empat TK di Kabupaten Kudus. Pemilihan subjek dalam penelitian ini menggunakan purposive sampling. Jumlah subjek penelitian terdiri dari 160 anak. Peneliti menyimpulkan dari keseluruhan data, bahwa ada perbedaan antara sekolah yang terletak di kota dan dengan sosioekonomi yang lebih tinggi dibandingkan dengan sekolah yang berada di pinggiran kota. Walaupun secara kategorisasi tidak jauh berbeda, namun secara rata-rata skor tiap anak menunjukkan perbedaan.
\end{abstract}

Kata kunci : Kesiapan sekolah, anak prasekolah.

\begin{abstract}
This research was conducted to find out level of school readiness of children. Analysis was carried out to find out the needs most needed to improve the quality of preschool education in Kudus district. This study used quantitative and qualitative data collection methods. Quantitative data was taken using Denver II psychological test tool, Bender-Gestalt II, Child Development Inventory (CDI), while qualitative data used observation and interview techniques. The research subjects were 40 kindergartens (TK) with details of 20 kindergartens $A$ and 20 kindergarten children B consisting of four kindergartens in Kudus Regency. Selection of subjects in this study using purposive sampling. The number of research subjects consisted of 160 children. Researchers concluded from the overall data, that there are differences between schools located in cities and with socioeconomics that are higher than schools located in the suburbs. Although categorically not much different, on average the score of each child shows a differences.
\end{abstract}

Keywords: School readiness, Preschool children

(C) 2018 Universitas Muria Kudus 


\section{PENDAHULUAN}

Pendidikan untuk anak yang paling mendasar adalah pendidikan prasekolah. Masa prasekolah merupakan masa yang penting bagi perkembangan kemampuan kepribadian, emosional, sosial dan kognitif (Katz, 1999). Perkembangan anak usia dini dan pendidikannya, bukan merupakan satu-satunya peran orang tua, namun institusi pendidikan prasekolah juga mempunyai peranan yang penting (Berliner D.C \& Caljee. RC, 1999). Kualitas pendidikan prasekolah tentunya menjadi perhatian utama dalam mempersiapkan masa depan anakanak. Penelitian empiris secara konsisten menunjukkan bahwa anak yang dapat mempersiapkan diri lebih baik di sekolah berhubungan erat dengan kesuksesan dalam sekolah dan kehidupannya kedepan (Matthews, Kizzie, Rowley, \& Cortina, 2010; Pianta, Barnett, Burchinal, \& Thornburg, 2009). Dalam mendukung upaya peningkatan kualitas pendidikan, maka diperlukan data dengan valid dan reliable terkait kesiapan sekolah anak.

Anak-anak yang menguasai kesiapan sekolah ketika mereka masuk ke taman kanakkanak dapat menguasai konsep baru dengan lebih cepat, berinteraksi lebih kompeten dengan guru dan temannya, dan mengatur sendiri perhatiannya, emosi dan perilaku untuk menyesuaikan diri dengan pengalaman ketika berada di sekolah (Blair, 2002). Kesiapan sekolah melibatkan pengendalian kemampuan dan sikap dasar yang menentukan anak untuk sukses di lingkungan sekolah, beradaptasi dengan dirinya sendiri pada tingkatan akademis dan sosial (Hair \& al, 2006). Anak-anak sering menunjukkan kesiapan yang berbeda khususnya di keahlian sosioemosional dan kognitif (Skinner, 1984). Kesiapan sosioemosional dan kognitif sangat penting dalam memprediksi pencapaian mereka di masa mendatang. Anak yang kurang dalam kesiapan sekolah kemungkinan kecil akan sukses secara akademis dan cenderung mengalami permasalahan emosi dan perilaku. Hingga saat ini, penelitian tentang kesiapan sekolah difokuskan pada beberapa tingkatan keahlian. Studi menunjukkan bahwa semakin tinggi keahlian matematika dan literasi saat sekolah berpeluang lebih sukses dalam pencapaiannya (Duncan dkk., 2007), dan lebih tinggi tingkat agresivitas dan perilaku mengganggu berpeluang terganggu secara sosial dan pencapaian akademis (Bierman dkk., 2013). Narendra dan Moerhadi (2007) menyatakan bahwa kematangan emosional anak meliputi kemampuan untuk dengan segera memperhatikan, misalnya tidak berbicara dengan teman di sebelahnya saat pengajaran berjalan, tetap mengikuti latihan yang berulang yang mungkin membosankan, dan tidak menangis setiap mengalami kegagalan. Rasa percaya diri, rasa ingin tahu yang sehat, suka mencoba pengalaman yang baru dan mempunyai beberapa kemampuan berpikir sebelum melakukan sesuatu, merupakan aset penting untuk anak dalam memulai sekolah. Narendra dan Moerhadi (2007) juga menyatakan bahwa perkembangan sosial meliputi ketrampilan yang kita pelajari untuk berinteraksi dengan orang lain secara efektif. Pengetahuan tentang perilaku yang bisa diterima atau budi pekerti yang baik, menghargai orang lain, kemampuan mengontrol diri, bekerjasama dengan orang lain dan 
berkomunikasi dengan cara yang bisa diterima akan membantu anak dalam proses integrasi dikelas dan menjadi bagian dari kelompoknya.

Kesiapan sekolah juga dipengaruhi oleh tingkat sosioekonomi. Rata-rata, anak dengan pendapatan keluarga rendah, latar belakang lingkungan yang berisiko menunjukkan rendahnya kesiapan sekolah dan tingginya agresivitas dan perilaku mengganggu dibandingkan dengan anak lain dengan pendapatan keluarga yang lebih tinggi (BulotskySheare \& Fantuzzo, 2012; Ryan, Fauth, \& Brooks-Gunn, 2006).

Analisa dan pengukuran kesiapan sekolah anak menjadi hal yang penting sebagai titik awal perbaikan kualitas pendidikan prasekolah di kabupaten Kudus. Peneliti tertarik untuk melakukan pengukuran kesiapan sekolah anak untuk kemudian dianalisa sebagai dasar pengembangan kualitas sekolah taman kanak-kanak.

Penelitian ini fokus pada analisa dan pengukuran kesiapan sekolah anak di kabupaten Kudus. Penelitian akan dilakukan untuk mengetahui seberapa besar tingkat kesiapan sekolah anak. Analisa dilakukan untuk mengetahui kebutuhan yang paling diperlukan untuk meningkatkan kualitas pendidikan prasekolah di kabupaten Kudus.

\section{METODE PENELITIAN}

Penelitian ini menggunakan metode pengambilan data kuantitatif dan kualitatif. Data kuantitatif diambil dengan menggunakan alat tes psikologi yang sudah sesuai dengan standar, dengan tingkat validitas dan reliabilitas yang dapat dipertanggung jawabkan secara empiris. Data kualitatif menggunakan teknik observasi dan wawancara, dengan panduan observasi dan wawancara yang dibuat sesuai kaidah-kaidah kelimuan khususnya ilmu psikologi.

1. Subjek Penelitian

Subjek penelitian adalah 40 anak TK dengan rincian 20 anak TK A dan 20 anak TK B yang terdiri dari empat TK yang sudah dipilih oleh peneliti. Pemilihan subjek dalam penelitian ini menggunakan purposive sampling. Jumlah subjek penelitian terdiri dari 160 anak.

Pengambilan sampel berdasarkan purposive sampling adalah pengambilan data berdasarkan kriteria tertentu yang ditentukan oleh peneliti. Penentuan pemilihan TK didasarkan pada lokasi perkotaan dan pinggiran kota serta pada kondisi sosioekonomi dari keluarga anak-anak yang bersekolah di empat TK tersebut.

2. Instrumen Penelitian

Instrumen yang digunakan menggunakan alat tes Denver II, Bender-Gestalt II, Child Development Inventory (CDI), observasi dan wawancara.

\subsection{Tes Denver II}

Denver II dibuat untuk memantau perkembangan anak secara berkala dan juga untuk menemukan secara dini masalah penyimpangan perkembangan potensial anak berumur 0-6 tahun. Denver II merupakan revisi dari Denver Development Screening Test (DDST) yang kali pertama dipublikasikan pada tahun 1967. Penggunaan DDST sudah secara luas dilakukan 
untuk menjaring kurang lebih 50 juta anak di seluru dunia. DDST berubah menjadi Tes Denver II pada tahun 1992. Tujuan utama dari Denver II adalah menilai tingkat perkembangan anak sesuai dengan kelompok umurnya pada saat dites. Denver II juga digunakan untuk memonitor perkembangan bayi dengan risiko tinggi adanya penyimpangan/kelaian perkembangan yang perlu mendapatkan prioritas.

\subsection{Bender-Gestalt II}

The Bender Gestalt Test digunakan untuk mengevaluasi kedewasaan visual, keterampilan motorik integrasi visual, gaya menanggapi, reaksi terhadap frustrasi (diagnosis klinis), kemampuan untuk mengoreksi kesalahan, dan organisasi keterampilan perencanaan, dan motivasi. Menyalin angka memerlukan keterampilan motorik halus, kemampuan untuk membedakan antara visual stimuli, kapasitas untuk mengintegrasikan keterampilan visual dengan keterampilan motorik, dan kemampuan untuk mengalihkan perhatian dari desain asli untuk apa yang sedang ditarik. Dari alat tes Bender-Gestalt ini, kita dapat mengetahui ada atau tidaknya gangguan fungsi kognitif pada anak usia 5-10 tahun. Administrasi alat tes ini mudah, cepat (hanya terdiri dari desain), dan tes dilaksanakan seperti dalam situasi bermain (karena anak hanya diminta menggambar/menyain).

\subsection{CDI}

Child Development Inventory (CDI) mengukur perkembangan terkini anak yang meliputi kelebihan anak dan kemungkinan masalah yang ada pada diri anak. Untuk usia anak sebelum sekolah, CDI juga mengukur kesiapan sekolah. Pengenalan angka dan huruf penting untuk menentukan kesiapan sekolah anak-anak. CDI juga digunakan untuk mengukur kemajuan perkembangan untuk anak-anak tertentu. CDI digunakan secara luas di setting pendidikan dan kesehatan serta sudah diterima di berbagai negara, Spanyol, Jerman, Perancis, Polandia, Cina, Jepang, Korea, Portugis dan Arab.

\subsection{Observasi dan Wawancara}

Observasi dan wawancara berdasarkan daftar centang perkembangan anak. Daftar ini merupakan skala tetap yang sudah di validasi. Skala ini disadur dari Observing Development of the Young Child (Janice, 2013).

\section{HASIL DAN PEMBAHASAN}

Hasil penelitian berupa gambaran umum tiap kelas dan sekolah serta gambaran khusus. Berikut adalah gambaran umum tiap sekolah berdasarkan jumlah rata-rata skor. Jumlah rata-rata skor yang didapat berdasarkan pembagian jumlah anak dengan jumlah skor keseluruhan aspek. Jumlah skor tertinggi yang bisa didapat untuk tiap aspek adalah sebesar 10 dan terendah sebesar 1. 
Tabel 1 Perbandingan rata-rata skor tiap sekolah

\begin{tabular}{c|c}
\hline Sekolah & Rata-rata \\
\hline CN & 72,38 \\
\hline M & 69,1 \\
\hline P & 59,38 \\
\hline MU & 64,18 \\
\hline
\end{tabular}

Tabel 1 menunjukkan profil secara keseluruhan berdasarkan rata-rata skor. Rata-rata skor yang didapat adalah jumlah total seluruh aspek pada TK A dan TK B dibagi 40 anak. TK $\mathrm{CN}$ dengan rata-rata skor tertinggi dan TK $\mathrm{P}$ dengan rata-rata skor terendah. Perbedaan ratarata skor terlihat signifikan antara TK $P$ dengan tiga TK lainnya.

Tabel 2 Perbandingan rata-rata skor Kelas A tiap sekolah

\begin{tabular}{c|c}
\hline Sekolah & Rata-rata \\
\hline $\mathrm{CN}$ & 68,4 \\
\hline $\mathrm{M}$ & 63,9 \\
\hline $\mathrm{P}$ & 54 \\
\hline $\mathrm{MU}$ & 60,6 \\
\hline
\end{tabular}

Tabel 2 menunjukkan profil sekolah berdasarkan kelas A. TK CN dengan jumlah ratarata skor tertinggi dan TK $\mathrm{P}$ dengan rata-rata skor terendah.

Tabel 3 Perbandingan rata-rata skor Kelas B tiap sekolah

\begin{tabular}{c|c}
\hline Sekolah & Rata-rata \\
\hline CN & 76,35 \\
\hline M & 74,3 \\
\hline P & 64,75 \\
\hline MU & 67,75 \\
\hline
\end{tabular}

Tabel 3 menunjukkan profil sekolah kelas B. Tabel menunjukkan hal yang sama, jumlah rata-rata skor tertinggi adalah TK CN dan terendah TK P. Terlihat perbedaan cukup signifikan antara TK P dengan TK CN dan TK M.

Berdasarkan tiga Tabel diatas, dapat disimpulkan bahwa profil keseluruhan TK A dan $B$ menunjukkan rata-rata skor kemampuan anak TK CN berada pada posisi pertama. TK M kedua dan disusul oleh TK MU. TK $P$ baik secara keseluruhan maupun pada kelas $A$ dan $B$ menunjukkan rata-rata skor terendah

Dua TK dengan rata-rata skor tertinggi yakni TK CN dan TK M. Rata-rata skor rendah yaitu TK $P$ dan TK MU. Hal ini terlihat dari keseluruhan data dan juga dari kedua data TK A dan TK B. Jika dilihat dari pemilihan subjek penelitian berdasarkan lokasi dan kondisi sosioekonomi, bisa disimpulkan bahwa TK yang terletak di daerah kota lebih tinggi rata-rata skor dibandingkan TK yang berada di pinggiran kota.

Peneliti menyimpulkan dari keseluruhan data, bahwa ada perbedaan antara sekolah yang terletak di kota dan dengan sosioekonomi yang lebih tinggi dibandingkan dengan 
sekolah yang berada di pinggiran kota. Walaupun secara kategorisasi tidak jauh berbeda, namun secara rata-rata skor tiap anak menunjukkan perbedaan.

Saat di sekolah, anak-anak dengan latar belakang pendapatan orang tua yang rendah, secara pencapaian akademik tertinggal jauh daripada anak-anak dengan latar belakang pendapatan orang tua yang lebih tinggi (Magnuson \& Duncan, 2006). Keilmuan dalam pendidikan prasekolah berhubungan erat dengan kosakata, mendengarkan dengan penuh perhatian dan keahlian fungsi eksekutif. Intruksi secara keilmuan yang disampaikan oleh guru sebagaian besar diabaikan, dan anak-anak usia prasekolah yang berasal dari keluarga dengan pendapatan rendah sangat kurang siap untuk hal ini (Greenfield, dkk, 2009). Anakanak dengan status sosial ekonomi rendah (Socio-Economic/SES) cenderung memiliki fungsi eksekutif dan pencapaian prestasi sekolah yang rendah dibandingkan dengan anak dengan SES menengah atau tinggi (Berliner \& Calfee, 1999). Psikometri dan studi pendidikan (Bradley \& Corwyn, 2002., Brook-Gunn \& Duncan, 1997), dan juga sub bagian studi paradigma neurokognitif (Berliner \& Calfee, 1999) sebagian besar membenarkan secara empiris pengaruh kemiskinan terhadap fungsi eksekutif. Secara umum, SES rendah mempengaruhi secara negative proses atensi, kendali perilaku, ingatan, fleksibilitas, perencanaan, kemampuan fonologis, regulasi diri dan konsep pemikiran pada bayi, taman kanak-kanak, sekolah dasar dan menengah.

Hal ini terlihat dari TK P dan TK MU. Secara infrastruktur masih belum memenuhi syarat untuk pembelajaran yang optimal. Hasil observasi dan wawancara menunjukkan sebagian besar orang tua bekerja sebagai buruh, atau bekerja di luar kota Kudus dengan pendapatan lebih rendah daripada orang tua di TK CN dan TK M. Penelitian menunjukkan bahwa perbedaan status SES dalam keluarga menghasilkan ketimpangan dimulai dari masa kanak-kanak yang bertahan seumur hidup (Berliner \& Calfee, 1999). Beberapa penelitian mengindikasikan bahwa anak-anak dari keluarga dengan SES rendah lebih besar mempunyai gejala psikologis dan gangguan fungsi adaptasi sosial dibandingkan keluarga dengan SES yang lebih tinggi (Brooks-Gunn \& Duncan, 1997; Yoshikawa, Aber \& Beardslee, 2012). Hasil observasi dan wawancara kepada anak membenarkan hal tersebut. Pada TK P dan TK MU, tester perlu mengulangi instruksi lebih dari satu kali agar anak paham. Adaptasi dengan lingkungan baru juga membutuhkan waktu yang lebih lama dibandingkan anak dari dua TK lainnya.

Perilaku dan perkembangan anak-anak pada tahun-tahun awal berhubungan dengan dukungan sosial yang mereka terima pada masa prasekolah (Berliner \& Calfee, 1999). Sangat penting bagi sekolah untuk mengadaptasi kurikulum yang menyediakan anak-anak kesempatan bermain yang memiliki peranan penting dalam pembelajaran anak-anak (Seifert \& Sutton, 2009). Selain kurikulum, lingkungan pembelajaran juga harus mendukung anakanak agar lebih optimal dalam mencapai hasil pembelajaran. 
Proses perkembangan dan pembelajaran anak melibatkan banyak aktivitas bermain. Anak-anak memiliki kecenderungan secara alami untuk bermain, dan hal itu berperan penting dalam perkembangan dan pembelajaran (Seifert \& Sutton, 2009). Acar (2014) menyatakan bahwa permainan mengembangkan bakat anak-anak dan potensi kreativitas anak. meningkatkan kemampuan bahasa, mental, sosial, emosional dan kemampuan motorik; menyediakan kesempatan belaajr melalui percobaan dan pengalaman yang dibutuhkan untuk kehidupannya mendatang.

Penghalang yang menghalangi kegiatan bermain dalam lingkungan mereka dapat menghambat kondisi psikologis dan fisiologis (Acar, 2014). Hal ini menunjukkan bahwa sekolah seharusnya didesain dengan lingkungan fisik yang sesuai yang bisa memberikan stimulus dan mendukung kegiatan bermain dan belajar yang menyenangkan dengan memberikan keleluasaan bagi anak anak untuk eksplorasi (Badzis, 2006). Sekolah yang dibangun tidak untuk menyenangkan orang dewasa namun memang didesain untuk meningkatkan peluang perkembangan anak (Badzis, 2006).

Lingkungan bermain didalam ruangan melibatkan tingkat kemampuan kognitif yang lebih tinggi yang terdiri dari tugas-tugas yang membutuhkan keterlibatan dan kepercayaan diri dalam setting pendidikan. Lingkungan luar ruangan sebaliknya, sering tidak mengindahkan setting pendidikan (Acar, 2014). Akses terhadap lingkungan bermain di luar ruangan sangat penting dalam memberikan stimulus kegiatan permainan fisik (Davison \& Lawson, 2006), yang memicu perkembangan motorik dan fisik serta mempromosikan perilaku sehat pada anak (Skinner, 1984). Interaksi dari permainan langsung melalui sentuhan, melihat dan mengalami alam juga merupakan factor pendukung dalam perkembangan emosi, motoric dan sosial. Sinar matahari selama bermain di luar ruangan akan meningkatkan kesehatan anak dan mengurangi risiko sindrom dalam ruangan yang biasanya terjadi pada anak dengan akses minim pada sinar matahari dan udara segar di dalam ruangan (Hansen \& Joshi, 2008).

Kualitas estetik dan spasial yang baik, fitur keamanan dan penggunaan bahan material yang sesuai, yang disesuaikan agar lingkungan kondusif untuk pengajaran dan pembelajaran. Kondusifitas lingkungan dalam ruangan diukur dengan menggunakan Indoor Environmental Quality (IEQ)- kenyamanan suara, suhu ruang dan visual. Kenyamanan lingkungan fisik mempengaruhi perilaku anak dalam bermain, yang akan mempengaruhi pembelajaran (Skinner, 1984).

Pengaturan ruang spasial juga mempengaruhi perkembangan anak, area yang dibuat sebaik mungkin akan mendorong perilaku positif dan belajar yang lebih baik (Seifert \& Sutton, 2009). Desain dan kualitas material berhubungan positif dengan perkembangan anak-anak prasekolah (Seifert \& Sutton, 2009). Studi menunjukkan bahwa lingkungan fisik yang didesain dengan baik akan mempengaruhi perkembangan secara luas, perkembangan perilaku yang positif terlihat ketika lingkungan fisik didesain dengan lebih baik (Reynolds \& Miller, 2003). 
Keterbatasan ruang fisik akan menghalangi perkembangan anak-anak karena hal tersebut menciptakan halangan terhadap perilaku, menyebabkan anak menjauhkan diri dan kurang menyatu dengan lingkungan sekitar (Reynolds \& Miller, 2003). Aspek dan dimensi fisik dari lingkungan fisik mempengaruhi perilaku dan sikap murid secara berbeda-beda (Reynolds \& Miller, 2003).

Lingkungan fisik sekolah mempengaruhi perkembangan dan kompetensi anak dengan banyak cara (Skinner, 1984). Lingkungan fisik dan perkembangan kognitif dan sosial anak erat kaitannya. Tujuan sekolah akan tercapai jika hubungan antara lingkungan sosial dan fisik juga bagus. Untuk menghasilkan lingkungan sekolah yang baik, program pengajaran harus didesain untuk dapat terintegrasi dengan infastruktur dan sebaliknya. Aktivitas pengajaran dan pembelajaran seharusnya tidak menghalangi akses namun memnfaatkan fasilitas yang ada. Sekolah yang didesain dengan baik, dilengkapi dengan kualitas estetika dan spasial yang baik, fitur keamanan dan kesesuaian penggunaan material dan perabotan membuat lingkungan semakin kondusif untuk pengajaran dan pembelajaran. Hal ini akan memaksimalkan pembelajaran dan perkembangan anak.

Dukungan orang tua secara kognitif kepada anak berimplikasi besar kepada kognitif dan metakognitif anak, dukungan emosi juga berhubungan erat dengan proses regulasi emosi dan motivasi anak, khususnya ketahanan anak terhadap tugas, kemauan mengerjakan tugas dan respon emosi terhadap tugas tersebut (Skinner, 1984). Tanpa dukungan emosional yang sesuai dari orang tua, anak mungkin akan kehilangan motivasi untuk belajar strategi kognitif atau untuk menerapkan pengetahuan baru ketika menyelesaikan permasalahannya sendiri (Stright dkk, 2001).

\section{KESIMPULAN}

Perkembangan kognitif anak dipengaruhi oleh banyak hal. Status sosial ekonomi merupakan salah satu faktor yang mempengaruhi perkembangan kognitif afektif dan psikomotoriknya. Hasil penelitian yang dilakukan oleh peneliti memberikan konfirmasi atas hal tersebut. Upaya untuk meningkatkan kemampuan anak dapat dilakukan dengan meningkatkan sumber daya lingkungan sekolah yang bertujuan untuk memberikan stimulus yang berguna untuk merangsang kemampuan kognitif dan psikomotorik anak. Guru juga memegang peranan penting dalam perkembangan anak-anak, terutama perkembangan emosi anak. Penelitian ini selanjutnya tampaknya harus menitikberatkan pada latar belakang orang tua dan sumber daya yang dimiliki oleh sekolah. Selain status sosial ekonomi, kapabilitas dan kapasitas guru juga berperan dalam perkembangan anak. Dengan mengetahui hal tersebut, tentunya upaya untuk meningkatkan kemampuan anak dapat dilakukan dengan baik dan terarah sesuai kebutuhan. 


\section{DAFTAR PUSTAKA}

Acar, A. Z. \& Acar, P., (2014). Organizational Culture Types and Their Effects on Organizational Performance in Turkish Hospitals. Emerging Markets Journal. 3(3), pp. 18-31

Badzis, M. (2006) Child Education : What Should be Optimal. Jurnal Pendidikan Islam, 12 (1). pp. 77-90. ISSN 0127-5153

Berliner. D.C, Caljee, R.C. (1999). Handbook of Educational Psychology. New York : Simon 7 Schuster Macmillan

Bierman, K. L., Coie, J., Dodge, K., Greenberg, M., Lochman, J., McMahon, R.,. \& The CPPRG. (2013). School Outcomes of Aggressive-Disruptive Children: Prediction from kindergarten risk factors and impact of the Fast Track Prevention Program. Aggressive Behavior, 39, 114-130. http://dx.doi.org/10.1002/ab.21467

Blair, C. (2002). School Readiness: Integrating Cognition and Emotion in Aneurobiological Conceptualization of Children's Functioning at School Entry. American Psychologist, 57, 111-127. http://dx.doi.org/10.1037/0003-066X.57.2.11

Bulotsky-Shearer, R. J., \& Fantuzzo, J. W. (2011). Preschool Behavior Problems in Classroom Learning Situations and Literacy Outcomes in Kindergarten and First Grade. Early Childhood Research Quarterly

Davison, K. K., Lawson, H. A., (2006). Do Attributes in The Physical Activity? A Review of The Literature. International Journal of Behavior Nutrition And Psysical Activity. Vol 3 : 1931. $10.1186 / 1479-5868-3-19$

Duncan, G. J., Dowsett, C. J., Claessens, A., Magnuson, K., Huston, A. C., Klebanov, P.,. \& Duckworth, K. (2007). School Readiness and Later Achievement. Developmental Psychology, 43, 1428-1446. http://dx.doi.org/10.1037/0012-1649.43.6.1428

Greenfield, E.A., Vaillant, G.E., \& Marks, N.F. (2009). Do Formal Religius Perticipation And Spiritual Perceptions Have Independent Linkages With Diverse Dimention Of Phychological WellBeing?. Journal of Health and Social Behavior. Vol 50: 196-212

Hair, E., Halle, T., Terry-Humen, E., Lavelle, B., \& Calkins, J. (2006). Children's school readiness in the ECLS-K: Predictions to Academic, Health, and Social Outcomes in First Grade. Early Childhood Research Quarterly, 21, 431-454. http://dx.doi.org/10.1016/j.ecresq.2006.09.005

Hansen, K. \& Joshi, H. (2008). "Millennium Cohort Study Third Survey: A User's Guide to Initial Findings." Centre for Longitudinal Studies, Institute of Education, University of London, London

Janice J.B. (2013). Observasi Perkembangan Anak Usia Dini Edisi Ketujuh. Jakarta: Kencana. (diterjemahkan dari buku aslinya Observing Development of The Young Child: Seventh Edition: Pearson Education, Inc) 
Katz, L. (1999). Another Look at What Young Children Should be Learning. Campaign, IL: ERIC Clearinghouse on Elementary and Early Childhood Education. University of Illinois

Magnuson, K.A. Duncan, G.J. (2006). The Role of Family Socioeconomic Resources in the Black-White Test Score Gap among Young Children. Developmental Review Journal 26. page 365-399. Elesvier. http://doi:10.1016/j.dr.2006.06.004

Matthews, J. S., Kizzie, K. T., Rowley, S. J., \& Cortina, K. (2010). African American Boys: Understanding the Literacy Gap Predicting Academic Trajectories and Evaluating Learning- Related Skills. Journal of Educational Psychology. 102, 757-771.

Narendra, M.B. \& Moerhadi, D. (2007). School Readinnes (Kesiapan Sekolah). Sari Pediatri Vol.8, No 4

Pianta, R. C., Barnett, W. S., Burchinal, M., \& Thornburg, K. R. (2009). The Effects of Preschool Education: What We Know, How Public Policy is or is Not Aligned with The Evidence Base, and What We Need to Know. Psychological Science in the Public Interest, 10, 49-88

Reynolds, W.M., Miller, G.E. (2003). Handbook of Psychology. Volume 7 Educational Psychology. John Wiley \& Sons, Inc

Ryan, R.M., Fauth, R.C., \& Brooks-Gunn, J. (2006). Childhood Poverty: Implications for School Readiness and Early Childhood Education. In B. Spodek, \& O.N. saracho (Eds.), Handbook of research on the education of children (2nd ed.,pp. 323-346). Mahwah, NJ: Erlbaum

Seifert, K. and Sutton, R. (2009). Educational Psychology. Retrieved March 13, 2013, from http://www.saylor.org/site/wpcontent/uploads/2012

Skinner, Charles. E. (1984). Educational Psychology Fourth Edition. Private Limited. Prentice Hall of India

Stright, Dkk. (2001). Instruction Begins In The Home: Relations Betwen Parental Instruction And Children's Self Regulation In The Classroom. Journal of Educational Psychology. APA. Vol. 93. No. 3, $456-466$

Yoshikawa, H., Aber, J. L., \& Beardslee, W. R. (2012). The Effects of Poverty on The Mental, Emotional, and Behavioral Health of Children and Youth: Implications for Prevention. American Psychologist, 67 (4), 272-284 http://doi:10.1037/a0028015 